1.1311）以及磷灰石高度贫 REE 为特征. 因此，应 用佛罪岩中磷灰石的 $\mathrm{Sr}$ 同位素和 $\mathrm{Rb} 、 \mathrm{Sr}$ 、 REE 等特 征来研究其成因、演化与矿化作用是有利的. 此外, 还可根据不同形成机理的伟晶岩之 $\left({ }^{87} \mathrm{Sr} /{ }^{86} \mathrm{Sr}\right)$ ap
比值与各种矿化类型的关系作为找矿评价标志.

伍勤生 刘青莲

（中国有色金属工业总公司矿产地质研究院，桂林）

\title{
华北棉区防治棉铃虫的新策略在 十万亩面积上应用成功*
}

华北棉区防治棉铃虫 (Heliothis armigera (Hübner））的传统策略是重点防治第二代、力保伏前桃， 经济间值定为百株棉花 15 粒卵或 5 头幼虫. 随着 生产条件的变化, 这一策略遇到了一些严重的经济 生态学问题. 为此, 中国科学院动物研究所运用系 统分析和经济生态学理论, 自 1980 年至 1985 年在 河北省饶阳县和安徽省滩溪县及涡阳县进行了一系 列试验研究, 提出在产量水平中等以上的棉田, 把 第二代经济阈值提高约 10 倍,并辅以合理的人工摘 蕾. 在 1983 年和 1984 年验证结果的基础上, 1985 年饶阳县全面推广这一新的技术策略, 实际应用面 积 10 万亩. 1985 年第二代棉输虫大发生, 百株累 计卵量为 557 粒, 仅施药一次, 容许幼虫为害一部分 蕾. 随后通过人工摘蕾, 使每株棉花总损失蕾数(包
括被害蕾)达到 4 个. 这样,节省用药 50\% 以上. 若 按 $2.5 \%$ 㴪氧菊酷 (Decamethrin) 乳剂计，全县节 省的农药为 2 吨左右. 此外, 每亩节约喷药用工半 个. 全县节约的农药及用工费估计为 17 万元.

今年棉花出苗比常年晚 10 天左右, 7、8 月降雨 $625.5 \mathrm{~mm}$ ，为常年均值的 $186 \%$ ，这些条件对棉花的 补偿不利。尽管如此，采用新的防治策略后仍显著 增产。通过比较 7 块地的处理区和对照区的实收籽 棉产量, 新策略平均增产 $21.39 \%$,合每亩籽桶 75.6 斤或 37.80 元. 这样,全县共获得经济净收益 395.0 万元.

\section{盛承发 李树清* 吴国伟 (中国科学院动物研究所,北京; *河北省绕阳县五公病虫测报站）}

\section{人淋巴细胞表面与羊红细胞结合的蛋白质*}

80 年代初作者等报道了人 $\mathrm{SRBC}$ 受体的分离提 纯及性质研究. 最近按 Mendes 法, 即以 SRBC 吸附 人淋巴细胞 $45^{\circ} \mathrm{C}$ 保温上清 (SHPL) 中的结合蛋白 质 $(\mathrm{BP})$, 免度自体羊. 按理, 在人淋巴细胞表面 与SRBC 结合的蛋白质即为 $\mathrm{SRBC}$ 受体. 但在分析了 SRBC 或其血影吸收 SHPL 后洗脱液中蛋白质的 PAGE 图谱, 却出现多条区带. 比较 SHPL 在 SRBC 吸收前后的数胶过滤图谱, 被吸附的蛋白质亦不限 于在一个峰上. 以此吸附蛋白质的 SRBC 免等自体 羊得抗 SRBC-Bp 抗血清, 提纯 IgO, 与 Sepharose4B 做成免度吸附柱, 用其分离人淋巴细胞和人 $\mathrm{T}$ 细胞 株 HPB-ALL 细胞 SHPL 或人血清中 Bp. 经 PAGE 和 SDS-PAGE (还原) 比较三者洗脱组分相符, 其主 要区带 MW 均在 I. $60,000-70,000$, II. 52,00059,000 及 III. $20,000-26,000$. 而 I 组与 II 组虽经

\footnotetext{
*中国科学院科学基金资助的课题.
}

高效液相 (HPLC) 亦难分离. 经 HPLC 纯化的 Bp 与 OKT11 反应阳性. 本文报道人淋巴细胞表面不止一 种蛋白质能与 SRBC 结合, 是前人所未注意到的.

文献报道多种抗人 SRBC 受体的单克隆抗体 (McAb) 所沉腚的蛋白质,不论还原或不还原, $\mathrm{MW}$ 均为 40,000-50,000 的一条钝链. 最近英国 Brown 获得一组 MW 在 50,000-58,000 间具有微不均一 性的糖蛋白, 即为 $\mathrm{SRBC}$ 受体 (现称 $\mathrm{CD}_{2}$ 抗原). 据此, 我们设想在本实验中多种 $\mathrm{Bp}$ 样品的 50,000 组分与 60,000 组分难以分离的现象很可能为一假象. 为此, 对 SRBC-BP 进行了在还原与不还原条件下的 SDSPAGE. 由于一般进行 SDS-PAGE 时样品处理(不论 还原或不还原)均需在沸水浴中加热 $5 \mathrm{~min}$ ，为避免 加热时对不还原 $\mathrm{Bp}$ 的影响，我们设计了一组不加热 亦不还原的处理样品方法 (称平衡法). 即将样品置 在含 $5 \% \mathrm{SDS}$ 的 $50 \mathrm{mmol} / 1$ Tris-acetate 缓冲液. $\mathrm{pH}$ 7.8 平衡过夜. 京批样品经三种处理在同一疑胶板 上做 SDS-PAGE. 三次实验结果如下表: 